\title{
Anthropometric measurements determinant nutritional status of urban primary school children in selected areas of Iran and India: A comparative study
}

\author{
Sahar Hooshmand, Shobha Udipi \\ Department of food science and nutrition, S.N.D.T. Women's University, Mumbai, India \\ Email address: \\ dr.s.hooshmand@gmail.com (S. Hooshmand),drshobhaudipi@gmail.com (S. Udipi)
}

\section{To cite this article:}

Sahar Hooshmand, Shobha Udipi. Anthropometric Measurements Determinant Nutritional Status of Urban Primary School Children in Selected Areas of Iran and India: A Comparative Study. International Journal of Nutrition and Food Sciences.

Vol. 3, No. 5, 2014, pp. 455-461. doi: 10.11648/j.jinfs.20140305.24

\begin{abstract}
Background: Malnutrition is a widespread problem in developing countries. Information on nutritional status of primary school children are not enough in Iran and India. The present study, made to assess prevalence of undernutrtion, stunting and wasting among urban school children in Mumbai in India and Ahwaz in Iran. Methods: Height and weight of 4570 including 2234 Iranian (1016 boys, 1218girls) and 2336 Indian (1240 boys, 1096 girls), aged 6-9 years, attending primary schools residing in Mumbai, India and Ahwaz, Iran were measured and the body mass index (BMI) calculated. The World Health Organization's (WHO) anthropometric indices of weight-for-age (WA) and height-for-age (HA) and weightfor-height were used to assess the children's nutritional status. Results: Underweight, stunting and wasting occurred in $3.2 \%$, $1.5 \%$ and $4.1 \% \%$ of Indian and $0.2 \%, 5.4 \%$ and $1.7 \%$ of Iranian children. WAZ mean scores of children were $-0.071 \pm 1.195$ for boys and $-0.287 \pm 3.241$ for girls in Iran and $-0.238 \pm 0.823$ for boys and $0.108 \pm 1.080$ for girls in India. HAZ mean scores were $-0.163 \pm 1.219$ for boys and $-0.515 \pm 3.141$ for girls in Iran and $-0.028 \pm 0.770$ and $-0.017 \pm 0.993$ for girls in India. BMI mean scores were $0.044 \pm 1.081$ for boys and $0.304 \pm 0.957$ for girls in Iran and $-0.345 \pm 0.796$ for boys and $-0.181 \pm 1.281$ for girls in India. Among Iranian children $0.2 \%\left(\chi^{2}=30.428, \mathrm{p}=0.000\right)$ and $3.2 \%$ Indian children had weight for age $\mathrm{z}$-scores below - $2 \mathrm{SD}\left(\chi^{2}=55.361, \mathrm{p}=0.000\right)$. Only $1.5 \%$ Indian children and 5.4\% Iranian children had height for age $z$-scores below -2SD $\left(\chi^{2}=11.553, p=0.000\right.$ and $\left.\chi^{2}=24.034, p=0.000\right)$. In Iran $1.7 \%$ and $4.1 \%$ of Indian children were wasted $\left(\chi^{2}=11.176, \mathrm{p}=0.004\right.$ and $\left.\chi^{2}=40.088, \mathrm{p}=0.000\right)$. Among Indian children, $1.3 \%$ had weight for height $\mathrm{z}-\mathrm{Scores}>+2 \mathrm{SD}$ compared to $3.6 \%$ Iranian children.
\end{abstract}

Keywords: Anthropometric Measurements, Nutritional Status, Schoolchildren

\section{Introduction}

Children constitute a sizeable proportion of the population and their health and nutrition is of concern. Under-nutrition is not just a state, but it is a process, the consequences of which often extend not only into later life, but also into future generations. Under-nutrition, specifically stunting is associated with impaired mental development and poor school performance. This association is not a simple casual one because complex environmental, social and economic factors are responsible. [1] A deficit in weight can be recouped if nutrition and health improve later in childhood. Once malnutrition is treated, adequate growth is an indication of health and recovery. Even after recovering from severe malnutrition, children often remain stunted for the rest of their lives, indicating that a deficit in height (stunting) is difficult to correct. [2] [3]

The best global indicator of children's well-being is growth. Assessment of growth is a measurement that best defines the nutritional and health status of children, and provides an indirect measure of the quality of life of the entire population. Growth during the school age which spans almost a decade is important because it contributes substantially to final adult stature. Data on the growth and nutritional status of 6-9 years school children generated in a consistent manner across countries and over time is difficult to find. This age group is important because food behavior and eating patterns are established at this age and 
determine the food choices and intake during adolescence and adulthood [4]

In almost all countries, the focus of nutritionists, medical and health professionals, policy makers and governments has been on children under five years of age. A long standing assumption has been that by school age, a child has survived the most critical period and is no longer vulnerable. However, many of the infectious diseases affecting preschool children persist into the school years. Schoolchildren may also be at high nutritional risk, not only under-five children. Because the prevalence of malnutrition in school children and adolescents is considerably less than those in children, relatively few studies have been carried out with school-age populations. In addition, limitations in establishing relations between anthropometric indicators and nutritional status in adolescents appear to have hindered research in this area (Prista, 1997). In India and Iran, data on the nutritional status of school-age children have not been routinely collected, despite evidence, that nutritional problems adversely affect school attendance, performance, and learning (UN, 2000).

However, their nutritional status is poorly documented, particularly in urban areas.[5] In India and Iran, data on the nutritional status of school-age children have not been routinely collected, despite evidence, that nutritional problems adversely affect school attendance, performance, and learning.[6] The aim of this study was to assess the nutritional status of Iranian and Indian government primary school children, 6-9 years of age, focusing on stunting, to provide baseline information about the prevalence and distribution of this problem among primary school children in both countries.

\section{Methods}

\subsection{Study Area}

This study was carried out in Mumbai city located in Maharashtra state of western India in Konkan division and in Ahwaz city which is situated in Khoozesan state in the south west of Iran. Mumbai possesses a mix of different socio economic groups. Both selected cities are one of the largest cities in India and Iran. Iranian group as a sample of non-vegetarian and Indian group as a sample of vegetarian diet pattern are selected for this study. The weather of Ahwaz city is similar to that of Mumbai with long extremely hot summer and mild short winters. In Iran, the major staple foods are bread, rice and non-vegetarian items. Beef and chicken are the main sources of protein. Fruits and vegetables are also grown and eaten in small quantity. In India, breads, legumes and pulses and vegetarian food items are consumed in large quantity.

\subsection{Study Sample}

Data for this study were obtained from a cross-sectional survey designed to evaluate the the nutritional status and body composition of children (aged 6-9 years) in Mumbai, Nigeria and Ahwaz, Iran.

The Principals of twelve governmental primary schools out of forty six schools from Ahwaz, Iran and seven governmental primary schools out of twenty schools from Mumbai, India were contacted through random sampling, who agreed to participate in the present study. The simple random sample is the basic sampling method assumed in statistical methods and computations. To collect a simple random sample, each school of the target population was assigned a number. A set of random numbers were then generated and the schools having those numbers were included in the sample.

Four thousand five hundred and seventy primary school children aged 6-9 years old (72-108 months) constituted the sample. From these, 2234 Iranian school children (1218 girls and 1016 boys) and 2336 Indian school children (1096 girls and 1240 boys) were included in the present study.

In all selected schools children within the age 6 and 9 years were eligible to participate in the study and were measured, 4570 participants eventually completed the anthropometric measures in 2009. These measurements were collected from October to December in Iran and in India from June to August by a team of fifteen trained research assistants in Iran and nine in India to conduct the interviews with the mothers in the study. Written informed consent was obtained from the participants' parents or guardians and school's principals. Permission for the study was granted by the S.N.D.T. Women's university Mumbai, India, ministry of education and training and ministry of health and medical education, Government of Iran. The study also received approval from the Ethics Committee of department of post graduate studies and research in home science S.N.D.T. Women's university, Mumbai, India.

\subsection{Anthropometric Measurements}

Height and weight were determined according to standard anthropometric methods (International Society for the Advancement of Kinanthropometry: ISAK). Height was measured to the nearest 0.1 centimeters $(\mathrm{cm})$ in bare feet with participants standing upright against a mounted stadiometer. Weight was measured to the nearest 0.1 kilogram $(\mathrm{kg})$ with participants lightly dressed using a portable Seca digital platform scale (model 770), calibrated periodically and regularly. BMI was computed as weight/height2 (kg m-2).

\subsection{Nutritional Status}

The World Health Organization's (WHO) AnthroPlus software which is a software for the global application of the WHO reference 2007 for 5-19 years to monitor the growth of school age children and adolescents was used to assess the nutritional status of the children. Three indicators were measured by this software: weight for age, height for age and BMI for age. The indicators were calculated by standard deviation (SD) or Z-score for all children. Weight 
for age, height for age and weight for height less than -3SD shows severe underweight, severe stunting and severe wasting. Weight for age, height for age and weight for height between -3SD to -2SD is classified as moderately underweight, moderately stunted and moderately wasted. Children with weight or height or weight for height between -2SD to and 2SD were classified as normal weight, normal height and normal BMI. Weigh for age, height for age and weight for height more than + SD were indicative of overweight, tall stature and obesity, respectively.

\subsection{Statistical Analysis}

The data was analyzed using the SPSS windows software version 17.0.Analysis was carried out separately for each country i.e. both for the Iranian children and Indian children. Also comparisons were made between the two countries. Means and standard deviations were computed for all variables. Anthropometric data always be presented together with $95 \%$ confidence intervals. Analysis of variance (ANOVA), post-hoc Bonferroni test and twotailed Student's t-test were used to compare different parameters which were studied. Chi - square test was used to determine independence of attributes within and between groups. Means and standard deviations were calculated for body mass, stature and BMI across sex and age groups. Differences in the mean body mass, stature and BMI were evaluated for boys and girls according to age-group, using an independent samples t-test. The $z$-scores of $<-2.0$ was calculated to derive HAZ and WAZ category of stunting and underweight, respectively.

\section{Results}

\subsection{Anthropometric Measurements}

The anthropometric characteristics of the Iranian and Indian school children are indicated in Table1. The median and mean values for all parameters were similar. Within country comparisons showed that mean weight of females was similar to that of male children. With respect to height, there was not much difference in the mean heights of the Indian girls and boys, however, in Iran; the mean height of the girls was approximately $2 \mathrm{~cm}$ more than boys. BMI of Indian girls and boys did not differ much. BMI of Iranian girls was slightly lower than boys.

Table 1. Anthropometric characteristics of the Iranian and Indian school children.

\begin{tabular}{|c|c|c|c|c|c|c|c|}
\hline \multirow{2}{*}{ Parameter } & \multirow{2}{*}{ Country } & \multicolumn{2}{|l|}{$\mathbf{n}$} & \multicolumn{2}{|c|}{ Mean \pm Std.Deviation } & \multicolumn{2}{|c|}{ Median } \\
\hline & & Boys & Girls & Boys & Girls & Boys & Girls \\
\hline \multirow{2}{*}{ Weight(kg) } & India & 1240 & 1098 & $23.9 \pm 5.0$ & $23.4 \pm 4.3$ & 23.2 & 22.7 \\
\hline & Iran & 1016 & 1216 & $23.7 \pm 4.2$ & $24.3 \pm 5.4$ & 23.3 & 23.5 \\
\hline \multirow{2}{*}{ Height(cm) } & India & 1240 & 1098 & $123.4 \pm 7.5$ & $123.5 \pm 7.7$ & 123.5 & 123.6 \\
\hline & Iran & 1016 & 1216 & $120.1 \pm 7.9$ & 122. $7 \pm 8.2$ & 120.9 & 123.0 \\
\hline \multirow{2}{*}{ Body Mass Index(BMI) } & India & 1240 & 1098 & $15.6 \pm 2.1$ & $15.2 \pm 1.4$ & 15.3 & 15.1 \\
\hline & Iran & 1016 & 1216 & $16.4 \pm 1.9$ & $15.9 \pm 2.2$ & 16.2 & 15.5 \\
\hline
\end{tabular}

\subsubsection{Weigh}

Table 2.a. Mean z scores for Weight for Age by Country, Sex and Age Group.

\begin{tabular}{|c|c|c|c|c|}
\hline \multirow{3}{*}{$\begin{array}{l}\text { Age } \\
\text { group }\end{array}$} & \multirow{2}{*}{\multicolumn{2}{|c|}{$\begin{array}{l}\text { Iran } \\
\text { Mean } \pm \text { SD }\end{array}$}} & \multicolumn{2}{|l|}{ India } \\
\hline & & & & \\
\hline & Boys & Girls & Boys & Girls \\
\hline $6-6.11$ & $0.041 \pm 1.350$ & $0.261 \pm 0.876$ & $-0.403 \pm 1.159$ & $0.002 \pm 0.971$ \\
\hline $7-7.11$ & $-0.109 \pm 1.235$ & $-1.236 \pm 6.246$ & $-0.379 \pm 0.641$ & $0.009 \pm 1.167$ \\
\hline $8-8.11$ & $0.276 \pm 1.030$ & $-0.046 \pm 0.501$ & $-0.164 \pm 0.637$ & $-0.065 \pm 0.876$ \\
\hline $9-9.11$ & $-0.498 \pm 0.990$ & $-0.121 \pm 0.697$ & $0.008 \pm 0.663$ & $-0.381 \pm 1.223$ \\
\hline Total & $-0.071 \pm 1.195$ & $-0.287 \pm 3.241$ & $-0.238 \pm 0.823$ & $0.108 \pm 1.080$ \\
\hline $\mathrm{F}, \mathrm{p}$ & $23.302,0.000$ & $10.750,0.000$ & $15.845,0.000$ & $9.231,0.000$ \\
\hline
\end{tabular}

Examination of mean $\mathrm{z}$ scores by age indicated that the nutritional status of Iranian boys and Indian girls was poorer in the older age groups than the younger age groups, as indicated by the increasing value of the standard deviation score in the negative range. In case of Iranian girls no clear cut trend was evident. Whereas for the Indian boys nutritional status appear to improve with age since the standard deviation (SD) scores shifted from a negative to a positive value. Differences between age groups for both boys and girls from both countries were statistically significant, with SD scores for Indian boys being lower than that for Iranian boys $(\mathrm{F}=14.911, \mathrm{p}=0.000)$. However $\mathrm{z}$ scores for girls did not differ significantly between the two countries $(\mathrm{F}=3.30, \mathrm{p}=0.068)$ (Table 2.a)

\subsubsection{Height}

Table 2.b. Mean z scores for Height for Age by Country, Sex and Age Group.

\begin{tabular}{lllll}
\hline \multirow{2}{*}{$\begin{array}{l}\text { Age } \\
\text { group }\end{array}$} & Iran & Mean \pm SD & & \multicolumn{4}{l}{ India } \\
\cline { 2 - 5 } & Boys & Girls & Boys & Girls \\
\hline $6-6.11$ & $0.228 \pm 1.263$ & $0.332 \pm 6.016$ & $-0.130 \pm 0.937$ & $0.075 \pm 0.985$ \\
$7-7.11$ & $-0.341 \pm 1.14$ & $-1.389 \pm 0.99$ & $0.119 \pm 0.688$ & $0.377 \pm 1.055$ \\
$8-8.11$ & $0.224 \pm 1.183$ & $-0.533 \pm 0.52$ & $-0.025 \pm 0.683$ & $-0.144 \pm 0.865$ \\
$9-9.11$ & $-0.768 \pm 0.97$ & $-0.468 \pm 0.58$ & $-0.081 \pm 0.721$ & $-0.390 \pm 0.892$ \\
Total & $-0.163 \pm 1.21$ & $-0.515 \pm 3.14$ & $-0.028 \pm 0.770$ & $-0.017 \pm 0.993$ \\
F,p & $53.337,0.000$ & $13.284,0.000$ & $5.572,0.001$ & $36.440,0.000$ \\
\hline
\end{tabular}

A significant difference was evident in height status of all age groups in India $(\chi 2=115.0088, p=0.000)$ and Iran $(\chi 2=274.320, p=0.000)$. When the data was examined for the different age groups, it was observed that stunting was highest among the 9-9.11 year old Indian children whereas in Iran, it was higher among the 7-7.11 year old children. 
The mean z-scores for height for age were computed and compared between age groups and between countries (Table 2.b).

\subsubsection{Weight for Height}

Mean weight for height $\mathrm{z}$ scores for the children from the two locations were examined (Table 2.c). In Iran, the mean $\mathrm{z}$ score for the girls for all ages combined was higher compared to their male counterparts. In all four age groups, the mean $\mathrm{z}$ scores for the girls were positive whereas for the boys, those who were in the age groups of 6-6.11 and 99.11 years had negative scores. Among the Indian children, overall the weight for height $\mathrm{z}$ scores of the boys was lower than that of their female counterparts. In each age group as well, the mean $\mathrm{z}$ scores for boys was lower than that of the female children. Comparison by age group within each country indicated that there was a significant difference between the four age groups, as seen in the table. For Iranian boys, the mean $\mathrm{Z}$ score was positive for boys between 7 and 8.11 years of age, suggesting that there may have been some weight gain associated with the prepubertal growth spurt. Among the girls, the mean values were higher for the girls between 6 and 7.11 years of age compared to the older girls. For the Indian children, the mean $\mathrm{z}$ scores were negative.

Table 2.c. Mean z scores for Weight for Height by Country, Sex and Age Group

\begin{tabular}{|c|c|c|c|c|}
\hline \multirow{2}{*}{$\begin{array}{l}\text { Age } \\
\text { group }\end{array}$} & \multicolumn{2}{|l|}{ Iran } & \multicolumn{2}{|l|}{ India } \\
\hline & Boys & Girls & Boys & Girls \\
\hline $6-6.11$ & $-0.031 \pm 1.11$ & $0.381 \pm 1.129$ & $-0.433 \pm 0.961$ & $-0.065 \pm 0.90$ \\
\hline $7-7.11$ & $0.118 \pm 1.40$ & $0.366 \pm 0.878$ & $-0.718 \pm 0.687$ & $-0.311 \pm 1.23$ \\
\hline $8-8.11$ & $0.182 \pm 1.071$ & $0.326 \pm 0.828$ & $-0.259 \pm 0.693$ & $-0.085 \pm 1.57$ \\
\hline $9-9.11$ & $-0.100 \pm 9.69$ & $0.141 \pm 0.954$ & $0.052 \pm 0.629$ & $-0.262 \pm 1.32$ \\
\hline Total & $0.044 \pm 1.081$ & $0.304 \pm 0.957$ & $-0.345 \pm 0.796$ & $-0.181 \pm 1.28$ \\
\hline $\mathrm{F}, \mathrm{p}$ & $4.435,0.004$ & $3.42,0.017$ & $51.258,0.000$ & $2.932,0.033$ \\
\hline
\end{tabular}

\subsection{Nutritional Status}

\subsubsection{Weight for Age Z-Scores}

A significant difference was observed in weight for age status based on Z-scores by gender of the school children in India $(\chi 2=55.361, p=0.000)$ and in $\operatorname{Iran}(\chi 2=30.428$, $\mathrm{p}=0.000)$. , majority of the children were found to have normal weight, although the percentage was lower for Iranian females than for their Indian counterparts. Almost 5 percent of the Iranian females were overweight as indicated by the $\mathrm{z}$ scores. Among males, a lower percentage of Indian boys had $\mathrm{z}$ scores in the normal range and approximately 5 percent were underweight and $1.7 \%$ was overweight. These percentages were higher than in the Iranian male children. Within country comparisons, between males and females indicated that a higher percentage of Iranian females than Iranian males were overweight. In India, a higher percentage of boys were moderately underweight and a small percentage of boys were overweight in contrast to a smaller percentage of girls. The differences between the two countries were statistically significant $(\chi 2=51.454$, $\mathrm{p}=0.000)$.

A significant difference was observed in weight for age $z$-scores by age groups of school children in India $(\chi 2=75.702, p=0.000)$ and in $\operatorname{Iran}(\chi 2=20.081, p=0.017)$. Severe underweight in both countries were observed only in the children 6-6.11 years of age. Overall in India, percentage of moderately underweight children increased with increasing age whereas in Iran the percentage of children in this category was higher among those who were 7-7.11 years of age. In both countries, more children with normal weight (-2SD to $+2 \mathrm{SD}$ ) were observed among 88.11 year of age than other age groups. Over weight school children were more among those who were 7-7.11 year of age (Table 3.a).

Table 3.a. Distribution of Weight for Age Z-scores for School Children by Country and Age Groups.

\begin{tabular}{|c|c|c|c|c|c|c|c|c|c|}
\hline \multirow{2}{*}{ Weight for Age } & \multirow{2}{*}{ Location } & \multicolumn{2}{|c|}{ 6-6.11 yrs } & \multicolumn{2}{|c|}{$7-7.11$ yrs } & \multicolumn{2}{|c|}{ 8-8.11 yrs } & \multicolumn{2}{|c|}{ 9-9.11 yrs } \\
\hline & & $\mathbf{n}$ & $\%$ & $\mathbf{n}$ & $\%$ & $n$ & $\%$ & $\mathbf{n}$ & $\%$ \\
\hline \multirow{2}{*}{$>-3 \mathrm{SD}$} & India & 3 & 0.5 & 0 & 0.0 & 0 & 0.0 & 0 & 0.0 \\
\hline & Iran & 2 & 0.4 & 3 & 0.5 & 0 & 0.0 & 0 & 0.0 \\
\hline \multirow{2}{*}{$-3 \mathrm{SD}$ to $-2 \mathrm{SD}$} & India & 12 & 2.0 & 18 & 3.0 & 1 & 0.2 & 44 & 7.6 \\
\hline & Iran & 8 & 1.4 & 13 & 2.3 & 0 & 0.0 & 7 & 1.3 \\
\hline \multirow{2}{*}{$-2 \mathrm{SD}$ to $+2 \mathrm{SD}$} & India & 578 & 97.5 & 567 & 95.1 & 565 & 98.8 & 528 & 91.5 \\
\hline & Iran & 530 & 94.6 & 530 & 93.1 & 536 & 96.6 & 528 & 96.4 \\
\hline \multirow{2}{*}{$>+2 \mathrm{SD}$} & India & 0 & 0.0 & 11 & 1.8 & 6 & 1.0 & 5 & 0.9 \\
\hline & Iran & 20 & 3.6 & 23 & 4 & 19 & 3.4 & 13 & 2.4 \\
\hline
\end{tabular}

\subsubsection{Height for Age Z-Scores}

Table 3.b. Distribution of Height for Age Z-scores for School Children by Country and Age Groups.

\begin{tabular}{|c|c|c|c|c|c|c|c|c|c|}
\hline \multirow{2}{*}{ Height for Age } & \multirow{2}{*}{ Location } & \multicolumn{2}{|c|}{ 6-6.11 yrs } & \multicolumn{2}{|c|}{ 7-7.11 yrs } & \multicolumn{2}{|c|}{ 8-8.11 yrs } & \multicolumn{2}{|c|}{ 9-9.11 yrs } \\
\hline & & $\mathbf{n}$ & $\%$ & n & $\%$ & n & $\%$ & $\mathbf{n}$ & $\%$ \\
\hline \multirow{2}{*}{$>-3 \mathrm{SD}$} & India & 0 & 0.0 & 0 & 0.0 & 0 & 0.0 & 0 & 0.0 \\
\hline & Iran & 0 & 0.0 & 3 & 0.5 & 2 & 0.2 & 0 & 0.0 \\
\hline \multirow{2}{*}{$-3 \mathrm{SD}$ to $-2 \mathrm{SD}$} & India & 12 & 2.0 & 2 & 0.3 & 1 & 0.2 & 21 & 3.6 \\
\hline & Iran & 8 & 1.4 & 86 & 15.1 & 3 & 0.5 & 24 & 4.4 \\
\hline \multirow{2}{*}{$-2 \mathrm{SD}$ to $+2 \mathrm{SD}$} & India & 580 & 97.8 & 584 & 98 & 568 & 99.3 & 556 & 96.4 \\
\hline & Iran & 523 & 93.4 & 476 & 83.7 & 526 & 94.8 & 524 & 95.6 \\
\hline \multirow{2}{*}{$>+2 \mathrm{SD}$} & India & 1 & 0.2 & 10 & 1.7 & 3 & 0.5 & 0 & 0.0 \\
\hline & Iran & 29 & 5.2 & 4 & 0.7 & 24 & 4.3 & 0 & 0.0 \\
\hline
\end{tabular}


A significant difference was observed in height for age status Z-scores, by age groups of school children in India $(\chi 2=47.141 \mathrm{p}=0.000)$ and in $\operatorname{Iran}(\chi 2=195.063, \mathrm{p}=0.000)$. Severe stunting was observed among a very small percentage of 7-7.11 and 8-8.11 years old Iranian school children, whereas none of the younger children in the age group of 6$6.11 \mathrm{yrs}$ were severely stunted. Moderate stunting was higher among the 7-7.11 years old children. Among the Indian children, a small percentage of the 6-6.11 and 9-9.11 years old Indian children were moderately stunted. Distribution of children with normal heights (-2SD to $+2 \mathrm{SD})$ in all age groups did differ not much between the two countries; however, the percentage of Indian children with normal height were higher as against Iranian children in all age groups (Table 3.b).

\subsubsection{Weight for Height Z-Scores}

Table 3.c. Distribution of Weight for Height Z-scores for School Children by Country and Age Groups.

\begin{tabular}{|c|c|c|c|c|c|c|c|c|c|}
\hline \multirow{2}{*}{ Weight for Height } & \multirow{2}{*}{ Location } & \multicolumn{2}{|c|}{ 6-6.11 yrs } & \multicolumn{2}{|c|}{ 7-7.11 yrs } & \multicolumn{2}{|c|}{ 8-8.11 yrs } & \multicolumn{2}{|c|}{ 9-9.11 yrs } \\
\hline & & n & $\%$ & $\mathbf{n}$ & $\%$ & $\mathbf{n}$ & $\%$ & $\mathrm{n}$ & $\%$ \\
\hline \multirow{2}{*}{$>-3 \mathrm{SD}$} & India & 3 & 0.5 & 2 & 0.3 & 2 & 0.3 & 3 & 0.5 \\
\hline & Iran & 0 & 0.0 & 0 & 0.0 & 0 & 0.0 & 0 & 0.0 \\
\hline \multirow{2}{*}{$-3 \mathrm{SD}$ to $-2 \mathrm{SD}$} & India & 21 & 3.5 & 26 & 4.4 & 9 & 1.6 & 30 & 5.2 \\
\hline & Iran & 14 & 2.5 & 6 & 1.1 & 6 & 1.1 & 13 & 2.2 \\
\hline \multirow{2}{*}{$-2 \mathrm{SD}$ to $+2 \mathrm{SD}$} & India & 569 & 96.0 & 557 & 93.5 & 551 & 96.3 & 534 & 92.5 \\
\hline & Iran & 226 & 93.9 & 535 & 94 & 530 & 95.5 & 521 & 95.5 \\
\hline \multirow{2}{*}{$>+2 \mathrm{SD}$} & India & 0 & 0.0 & 11 & 1.8 & 10 & 1.7 & 10 & 1.7 \\
\hline & Iran & 20 & 3.6 & 28 & 4.9 & 19 & 3.4 & 14 & 2.6 \\
\hline
\end{tabular}

A significant difference was observed in weight for height status z-scores by age groups of school children in India $(\chi 2=22.959, p=0.006)$ and in $\operatorname{Iran}(\chi 2=10.549$, $\mathrm{p}=0.103)$. In India, moderate wasting was observed more in the age group of 7-7.11 and 9-9.11years; whereas in Iran, a higher percentage of moderately wasted children were observed in the age groups of 6-6.11 and 9-9.11 years, respectively. Among Iranian school children, the percentage of children with normal BMI (z scores between -2 and +2 SD) increased with increasing age, whereas for Indian children, there was no clear cut trend. The percentage of obese children $(>+2 \mathrm{SD})$ was higher in the age group of 7-7.11 years in Iran. In India none of the children in the age group of 6-6.11 years was obese. In the remaining three age groups there was no difference in the percentage of the children who were obese (Table 3.c)

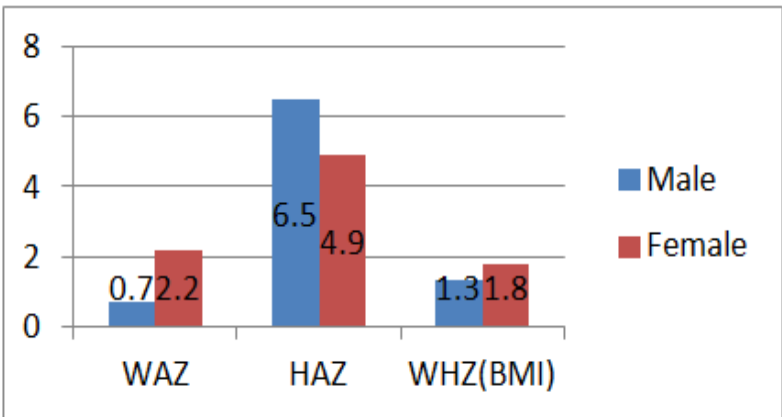

Figure 1.a. Nutritional status (<-2SD) for Iranian school children by Gender (\%).

In the Figures 1.a and 1.b are the nutritional status of Iranian and Indian school children stratified by gender are shown. In Iran, The prevalence of underweight status was higher in boys than the girls, and the difference was statistically significant $(\chi 2=30.428, \mathrm{p}=0.000)$. Also, boys tended to be more stunted compared to girls and the difference was statistically significant $(\chi 2=24.034$, $\mathrm{p}=0.000)$. Conversely, girls tended to be more wasted than boys $(\chi 2=24.034, p=0.004)$. Same trend was found in India; the prevalence of underweight status was higher in boys than the girls, and the difference was statistically significant $(\chi 2=55.361, p=0.000)$. Also, boys tended to be more stunted compared to girls and the difference was statistically significant $(\chi 2=11.553, \mathrm{p}=0.003)$. Boys were observed more wasted than girls $(\chi 2=40.088, \mathrm{p}=0.00)$.

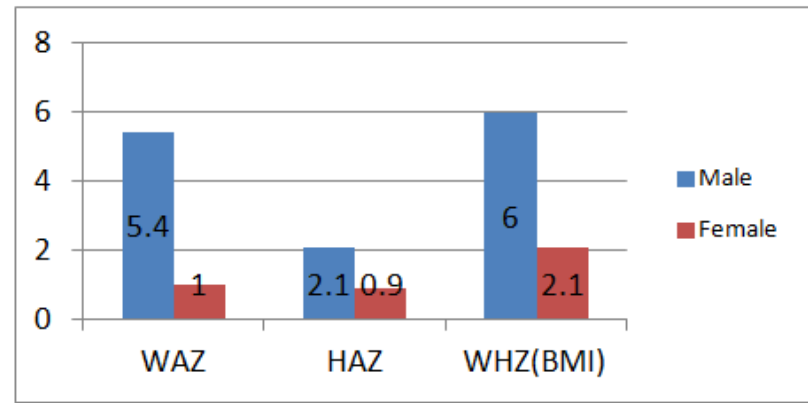

Figure 1.b. Nutritional status (<-2SD) for Indian school children by Gender.

\section{Discussion}

The study provides anthropometric data on the nutritional status in a group of school children in Ahwaz, Iran and in Mumbai, India. Nutritional status is an integral component of the overall health of an individual [7] and provides an indicator of the well-being of children living in a particular region. [8] In this regard, the importance of the nutritional status of children in the developing countries should be emphasized, not only for the improvement of health of children in the coming generation, but also for the 
overall development of the concerned region in near future.[9] The findings of this present study reflect a high prevalence of underweight and wasting among Indian schoolchildren and high prevalence of stunting among
Iranian schoolchildren. Data of the present study was compared with values reported by other authors in India and Iran (Table 4).

Table 4. Comparison of Mean Heights (cms) of Children in the Present Study with Values reported in Literature.

\begin{tabular}{lllllll}
\hline & \multicolumn{2}{l}{ Indian Children } & & \multicolumn{2}{c}{ Iranian Children } \\
\cline { 2 - 6 } Age group (yrs) & Boys & & Girls & Boys \\
\cline { 2 - 6 } & Manna et al., (2011) & Present study & Manna et al., (2011) & Present study & Present study & Aminoarraya et al., (2003) \\
\hline $6-6.11$ & $109.8 \pm 2.9$ & $115.5 \pm 5.1$ & $110.0 \pm 2.9$ & $114.5 \pm 4.7$ & $114.8 \pm 5.0$ & $118 \pm 5.4$ \\
$7-7.11$ & $115.6 \pm 3.7$ & $122.7 \pm 5.8$ & $116.4 \pm 4.9$ & $121.5 \pm 3.8$ & $113.1 \pm 5.3$ & $126 \pm 7.4$ \\
$8-8.11$ & $119.0 \pm 3.3$ & $125.6 \pm 5.0$ & $120.8 \pm 4.8$ & $126.4 \pm 3.9$ & $123.2 \pm 2.7$ & $129 \pm 6.5$ \\
$9-9.11$ & $122.1 \pm 4.3$ & $130.0 \pm 5.4$ & $123.6 \pm 3.3$ & $132.1 \pm 4.4$ & $129.6 \pm 3.5$ & $134 \pm 6.6$ \\
\hline
\end{tabular}

Mukherjee and his college study on 5-11 years school children in Pune, India demonstrated that the mean weight increased from $18.4 \mathrm{~kg}$ and $18.0 \mathrm{~kg}$ for boys and girls respectively in the $5+$ age group to $34.5 \mathrm{~kg}$ and $35.7 \mathrm{~kg}$ respectively in the $11+$ age group. The mean weight of boys was more than the girls till 8 years of age, thereafter the girls weighed more. However there was no statistically significant difference in the mean weights of the boys and girls in any of the age groups. [10]

The study by Prabhakar and Gangadhar [11] showed that about $41.5 \%$ of mild stunting (based on Waterlow's classification) was recorded in all age groups and both sexes, followed by moderate stunting in $39.3 \%$. Severe stunting was observed in $6.7 \%$ of children. This is much higher than the percentage of Indian children who were stunted in the present study.

Mukherjee study, wasting was observed in 22 (6.12\%) girls and $29(7.23 \%)$ boys; however this difference between sexes was not statistically significant. [10] These researchers did not report about the percentage of children who were overweight or obese. In a study conducted at SNDT Women's University in Mumbai, 7.7 percent of children aged 7 to 10 years were overweight and 13.2 percent were obese.[12] Phadke et al. observed that a higher percentage of boys were overweight or obese compared to girls. These observations are similar to trends observed in the present study. [12] In a previous study conducted by Lunn [13] a much higher percentage of children were found to be overweight and obese (57.4\%), with not much difference between boys and girls.

In the present study, mean BMI was lower compare to the values reported by Gopalakrishnan, which may be explained by differences in socioeconomic status. Children in the present study were enrolled in government subsidized schools whereas the sample studied by Gopalakrishnan was from upper income families attending private schools. In another study conducted recently, Pathak (2009), the mean BMI was in the range of 14.1 to 19.3; with higher BMI being observed for 9-10 year old girls. Mahajan and his coworkers in a study on school children in Union Territory of Puducherry, the prevalence of overweight and obesity was $4.98 \%$ and $2.24 \%$ respectively. [15] A similar finding was reported from another study in Kerala by Raj et al., indicated an increasing prevalence of overweight and obesity from $4.94 \%$ and $1.26 \%$ in 2003 to $6.57 \%$ and $1.89 \%$ in 2005 with particular rise in the age group 5-11 yrs. Andhra Pradesh had 2nd highest prevalence of overweight (5.68\%), and lowest prevalence of obesity $(0.57 \%)$. [16] A similar study among adolescents in Hyderabad by Laxmaiah reported prevalence of overweight of $7.2 \%$. In Puducherry and Karaikal regions surrounded by TamilNadu, the prevalence of overweight and obesity ranged from $2.87 \%$ to $3.91 \%$ and $1.78 \%$ to $2.59 \%$, respectively. A study carried out in urban school of Chennai, Tamil Nadu by Subramanyam et al. reported a high prevalence of overweight (8.0-10.81\%) and obesity (5.26-9.52\%).[17]Sharma et al., reported that obesity rates declined with age among children aged 4-17 years from Delhi. They suggested that as children become older they become more conscious about their looks and may restricts their dietary intake. [18]

The present study showed that majority of the children was well nourished although a small percentage of Iranian children were stunted. Overweight and obesity was noted in approximately $15-20 \%$ children from Iran and Indian boys. However, there is a need to determine the extent to which this is due to diet and life style patterns and the contribution of prepubertal changes in body composition, body weight and stature.

\section{Conclusion}

Most of children in both countries were well nourished. Stunting was more prevalent in Iran than India. In India children were more wasted than Iran. The percentage of stunted children was more in Iran than in India, and a slightly higher percentage of Iranian children tended to be overweight / obese compared to Indian children.

\section{Acknowledgements}

The authors of this work wish to acknowledge the technical assistant of Dr.J.C.Sharma for caring out the statistical analysis and the ministry of health and medical 
sciences of Islamic Republic of Iran and human resource development, Government of India. We would like to thank the all school's principals, teaching and non-teaching staff members of department of food science and nutrition for providing required help whenever needed.

\section{References}

[1] Beasley, D.A.; Wedge, J.H.; McCulloch, R.G.; Martin, A.D. and SC. Bernhardson. Epidemiology of fractures of the distal end of the radius in children as associated with growth. J Bone Joint Surgery Am 71:1225-1231, 2002.

[2] Walker, M.; Christopher, D.; John, B.; Watkins and W. Allan (2008) Nutrition in pediatrics: basic science, clinical application. Hamilton: BC Decker. pp. 127-141.

[3] UNICEF (2010) The State of the World's Children 2010. Oxford: Oxford University Press.

[4] Frank G.C. Changes in Women, Infants, and Children (WIC) Food Packages. Obesity Management; 2:96, 2008.

[5] Daboné, ch.; Hélène, F.; Delisle and R. Olivier. Poor nutritional status of schoolchildren in urban and peri-urban areas of Ouagadougou (Burkina Faso). Nutrition Journal, 10:34, 2011.

[6] United Nations (2000) World Population Prospects 19502050 (The 2000 Revision). New York: UN.

[7] Som S, Pal M, Bharati P. Role of individual and household level factors on stunting: a comparative study in three Indian states. Ann Hum Biol, 34:632-646, 2007.

[8] Dutta, A.; pant, K.; Puthia, R.; Sah, A. Prevalence of undernutrition among children in the Garhwal Himalayas. Food and Nutr Bull, 30:77-81, 2009.

[9] Rao, VG.; Yadav, R.; Dolla, CK.; Kumar, S.; Bhondeley, MK.; Ukey, M. Undernutrition and childhood morbidities among tribal preschool children. Indian J Med Res, 122:4347, 2005.
[10] Mukherjee R. Determinants of Nutritional Status of School Children. Medical journal of armed forces of India; 64: 227231, 2008.

[11] Prabhakar, SC. and MR. Gangadhar. Nutritional status of Jenukuruba tribal children in Mysore District, Karnataka. Anthropologist, 11: 83-88, 2009.

[12] Phadke MA, Gadgil B, Bharucha KE, Shrotri AN, Sastry J, Gupte NA, Brookmeyer R, Paranjape RS, Bulakh PM, Pisal $\mathrm{H}$, et al.: Replacement-fed infants born to HIV-infected mothers in India have a high early postpartum rate of hospitalization. J Nutr, 133(10):3153-3157, 2003.

[13] Lunn P.G. Growth retardation and stunting of children in developing countries. British journal of nutrition; 88:109$110,2002$.

[14] Pathak P.K. Socioeconomic inequality in malnutrition in India, 1992-2005. Paper to be presented at the annual meeting of Population Association of America (PAA) at Detroit, Michigan, USA. 2009.

[15] Mahajan P.B., Purty A., Singh Z., Cherian J., Natesan M., Arepally S. and V. Senthilvel. Study of Childhood Obesity Among School Children Aged 6 to 12 Years in Union Territory of Puducherry. Indian J Community Med 36(1): 45-50, 2011.

[16] Raj M., Sundaram K.R., Paul M., Deepa A.S. and R.K. Kumar. Obesity in Indian children: Time trends and relationship with hypertension. Natl Med J India ;20:288-93, 2007.

[17] Subramanyam, V.; Jayashree, R. and M. Rafi (2003) Prevalence of overweight and obesity in affluent adolescent girls in Chennai in 1981 and 1998. Indian Pediatr ; 40:332-6.

[18] Sharma.;B., Mitashree, M.; and Chakrabarty, S. and P. Bharati . Nutritional status of preschool children of Raj Gond - a tribal population in Madhya Pradesh\| India. Malaysian Journal of Nutrition, 12 (2). pp. 147-155, 2006. 